\title{
Long Live the Modern: New Zealand's New Architecture, 1904-1984
}

\section{Curated and designed by Bill McKay and Julia Gatley}

Long Live the Modern was held at the Gus Fisher Gallery, The University of Auckland, from 17 October to 22 November 2008. It was curated in conjunction with the launch of the Julia Gatley-edited book of the same title, published by Auckland University Press. It coincided with Constructing the Modern City: Canterbury Architecture, 1940-1970, curated by lan Lochhead and Jessica Halliday and held at Christchurch's COCA Gallery from 14 October to 2 November 2008. Both exhibitions celebrated New Zealand's modern architecture and encouraged increased heritage listing and registration of our modern buildings.

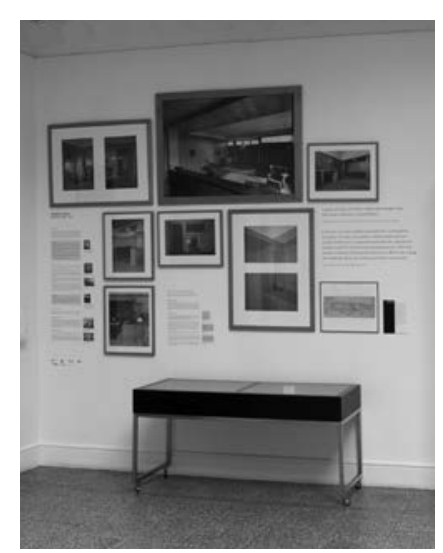

Henry Kulka exhibits provided by the Kulka Foundation. Photograph by Sam Hartnett.

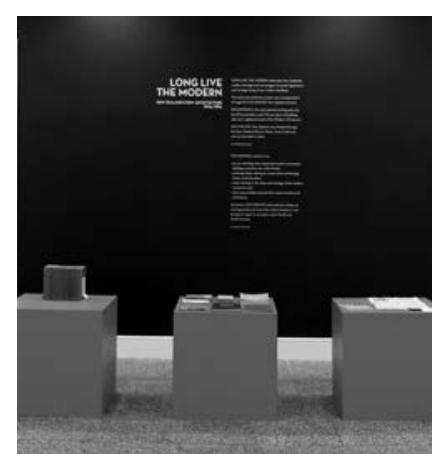

Inside Gallery 1, the black wall explained the role of DOCOMOMO, the international working party for the DOcumentation and COnservation of buildings, sites and neighbourhoods of the MOdern MOvement. Photograph by Sam Hartnett.

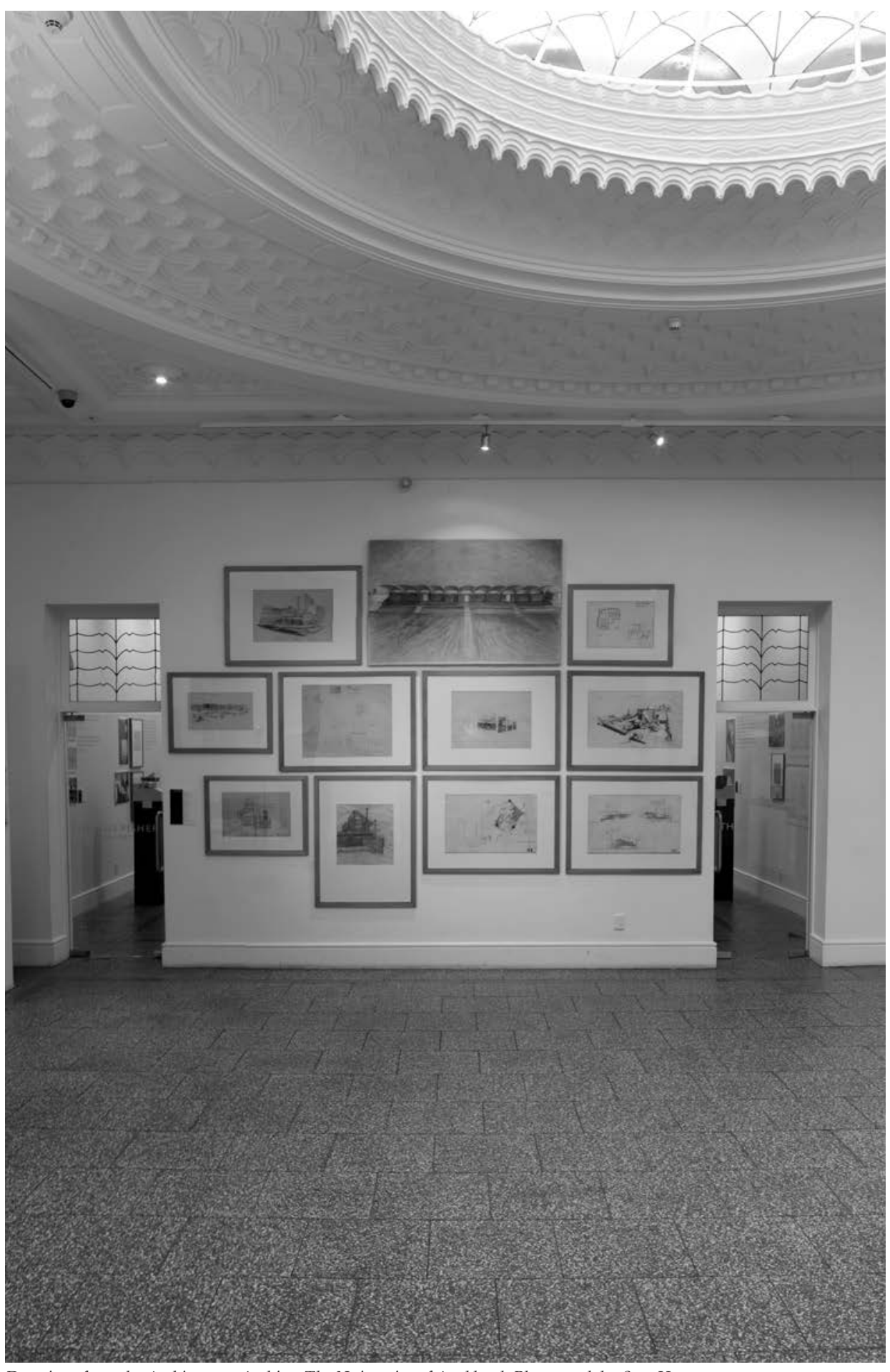

Drawings from the Architecture Archive, The University of Auckland. Photograph by Sam Hartnett. 

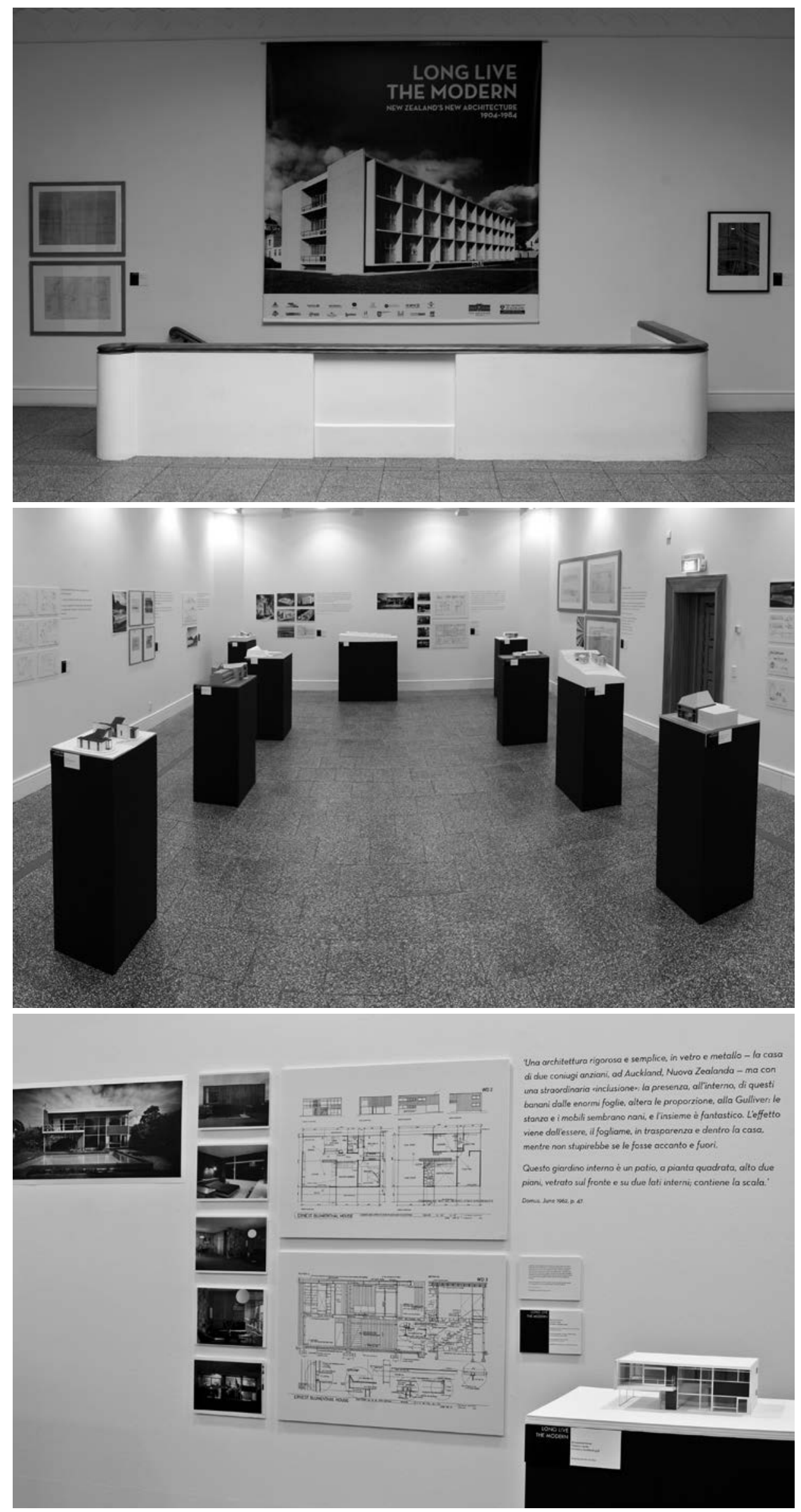

The banner sports the book cover. Photograph by Sam Hartnett.

Gallery 1 contained drawings, models, photographs and text focusing on eleven of the 180 buildings included in the book. Photograph by Sam Hartnett.

An example of one of the eleven 'stations' Vladimir Čačala's Blumenthal House, St Heliers, Auckland, 1958. New photograph by Simon Devitt; period photographs by Ted Mahieu / collection of Bill McKay; and model by Clio Kei-Yan Chiu. Photograph by Sam Hartnett. 